\title{
Awareness regarding Antenatal Investigations among Antenatal Mothers attending Selected Tertiary Hospital, Kochi, Kerala
}

\author{
${ }^{1}$ Seethu Udayan, ${ }^{2}$ Lekha Viswanath, ${ }^{3}$ Linda Varghese
}

\begin{abstract}
Background: An antenatal investigation has now literally entered in the domain of prenatal care. Early antenatal investigations help to identify many sorts of medical and infectious diseases during pregnancy and initiate treatment for safeguarding the health of mother and fetus. Many antenatal mothers undergo antenatal investigations without adequate understanding.
\end{abstract}

Objectives: To identify awareness regarding antenatal investigations among antenatal mothers and to prepare an information booklet on antenatal investigations.

Materials and methods: It is a descriptive study conducted among 180 antenatal mothers attending Obstetrics and Gynecology Outpatient Department in Amrita Institute of Medical Sciences (AIMS) at Kochi. The subjects were selected using quota sampling technique. The trimester was selected as the quota. Sixty women each were selected from first, second and third trimesters. Data were collected using semistructured knowledge questionnaire developed by the investigator.

Results: The mean score of antenatal investigations was $8.96 \pm$ 6.33 with maximum score 19 . Among 180 subjects, $61 \%$ of antenatal mothers had poor level of awareness regarding antenatal investigations, $63 \%$ were belong to first trimester and $64 \%$ were primigravida.

Interpretation and conclusion: The study concluded that the level of awareness among antenatal mothers was poor. It is very essential to organize an awareness program to increase the uptake of antenatal investigations.

Keywords: Awareness, Antenatal investigations, Antenatal mother, Information booklet.

How to cite this article: Udayan S, Viswanath L, Varghese L. Awareness regarding Antenatal Investigations among Antenatal

\footnotetext{
${ }^{1}$ Postgraduate Student, ${ }^{2}$ Associate Professor

${ }^{3}$ Assistant Professor

1-3Department of Obstetrics and Gynecology Nursing, Amrita College of Nursing, Amrita Vishwa Vidyapeetham, Health Sciences Campus, Amrita Institute of Medical Sciences, Kochi Kerala, India

Corresponding Author: Lekha Viswanath, Associate Professor, Department of Obstetrics and Gynecology Nursing Amrita College of Nursing, Amrita Vishwa Vidyapeetham Health Sciences Campus, Amrita Institute of Medical Sciences Ponekkara (PO), Kochi, Pin-682041, Kerala, India, Phone: 0484-4008200, e-mail: lekhaviswanath3@gmail.com
}

Mothers attending Selected Tertiary Hospital, Kochi, Kerala. J South Asian Feder Obst Gynae 2014;6(3):129-132.

\section{Source of support: Nil}

Conflict of interest: None

\section{INTRODUCTION}

Antenatal investigations are the procedures performed during pregnancy to detect health problems in the growing fetus, or diagnose any maternal conditions that may affect fetal development. ${ }^{1}$ In a country like India, many women face lot of health problems during pregnancy, such as anemia, gestational diabetes mellitus, hyperthyroidism, hypothyroidism, urinary tract infection, hepatitis B infection, etc. In India, anemia is a major health problem during pregnancy. NFHS-3 (2013) estimated that $58 \%$ of pregnant women in India are anemic in which $32.2 \%$ of anemic cases detected in Kerala in the year of 2013. ${ }^{2}$ The prevalence of GDM is high in India due to the ethnic predisposition. It is most commonly seen in women living in urban than in rural areas. ${ }^{3}$ The national aids control program (NACP) III reported that in India nearly $5 \%$ of HIV infections are acquired through parent to child transmission. ${ }^{4}$ Early antenatal investigations help to sort these type of medical and infectious disorders and initiate treatment to safeguard the life of the mother and baby.

Antenatal screening will provide reassurance that the chances of their baby having any problems are very low. Hence, all antenatal mothers should be giving with proper instructions and guidance before performing each test. Improper physical preparation may lead to inappropriate test results usually seen in the result of urine culture, glucose challenge test (GCT), glucose tolerance text (GTT) and thyroid stimulating hormonc (TSH). Literature studies reported that majority of antenatal mothers undergo antenatal investigations without knowing its purpose and importance. ${ }^{5}$

The researcher observed many antenatal mothers attending Obstetrics and Gynecology Outpatient Department at AIMS, Kochi, had lot of queries regarding need of antenatal investigations, its purpose, timing, methods and preparations required. Hence, the researcher feels that it is very essential to assess the level of awareness 
regarding antenatal investigations with a view to develop an information booklet.

\section{MATERIALS AND METHODS}

The study used a quantitative approach with descriptive survey design. The sample consists of 180 antenatal mothers attending Obstetrics and Gynecology Outpatient Department at Amrita Institute of Medical Sciences, AIMS, Kochi. The data were collected during the period of November to December 2013. The participants were selected using quota sampling technique with trimester as the quota. Sixty subjects were selected from each trimester. Ethical clearance was obtained from Thesis Review Board of Amrita Institute of Medical Sciences. The data were collected using semistructured knowledge questionnaire developed by the investigator. The questionnaire consisted of 26 items. Each correct response carries one mark. Content validity of the tool was established from six experts. The content validity index was 0.96 . Reliability of the tool was 0.82 calculated using split half method. A detailed explanation is given to the subject before recruitment. After obtaining an informed consent, the subject given with semistructured knowledge questionnaire.

\section{RESULTS}

Most of the antenatal mothers, 91 (51\%), belonged to the age group of 26 to 30 years and, 103 (57\%), were graduates or postgraduates. Eighty participants (44\%) were received health-related information from newspaper/magazines and $76(42 \%)$ from friends/relatives.

Most of the participants, 96 (53\%), were primigravida and, 84 (47\%), were multigravida. Among the participants, 14 (36\%) had hypo/hyperthyroidism, 11 (28\%) had gestational diabetes mellitus and 9 (23\%) were anemic.

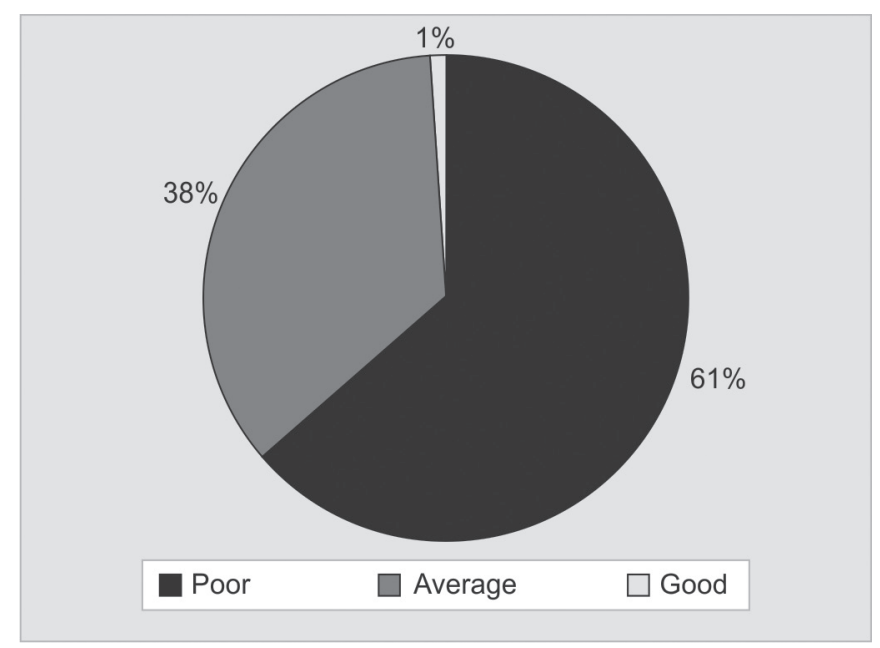

Graph 1: Distribution of participants based on the scores of awareness regarding antenatal investigations $(n=180)$
Majority of the subjects 172 (96\%) had awareness about own blood group.

\section{Awareness regarding Antenatal Investigations}

The study revealed that the mean score of antenatal investigations was $8.96 \pm 6.33$ (maximum score 26). Based on the score obtained, the awareness level of participants is categorized into good (19-26), average (10-18) and poor (1-9).

Distribution of participants based on level of awareness is given in Graph 1.

Graph 1 shows that awareness regarding antenatal investigation was poor among 109 (61\%) antenatal mothers and average among 69 (38\%) antenatal mothers. Only two (1\%) antenatal mothers had good level of awareness.

The awareness level of primigravida and multigravida mothers is presented in Graph 2.

Graph 2 shows that the level of awareness regarding antenatal investigations was poor in both primigravida (64\%) and multigravida mothers (55\%).

\section{Awareness in Different Areas of Antenatal Investigations}

Awareness was assessed on blood test, urine test and ultrasound scan during pregnancy.

Table 1 depicts that antenatal mothers scored better in the areas of urine test (65\%). The score was less than $50 \%$ in all other areas.

Comparison of awareness score in specific areas of antenatal investigations among antenatal mothers in first, second and third trimester is presented in Table 2.

Table 2 shows that one way ANOVA test was used to compare the specific areas of awareness regarding antenatal investigations among antenatal mothers in

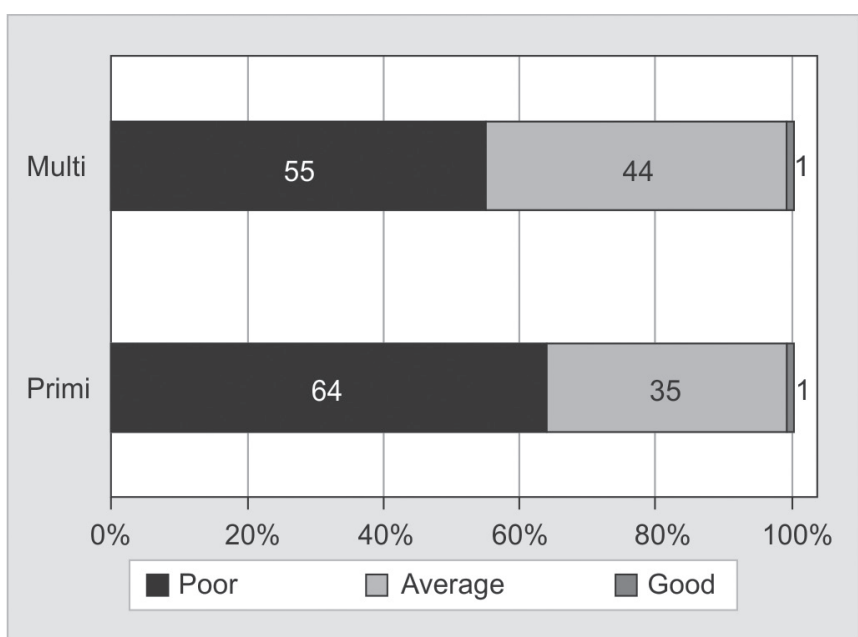

Graph 2: Awareness regarding antenatal investigations among primi and multigravida $(n=180)$ 
Awareness regarding Antenatal Investigations among Antenatal Mothers

Table 1: Mean score of awareness in different areas of antenatal investigations $(n=18)$

\begin{tabular}{llll}
\hline $\begin{array}{l}\text { Specific areas of } \\
\text { awareness level }\end{array}$ & Maximum score & $\begin{array}{l}\text { Mean score and } \\
\text { standard deviation }\end{array}$ & Mean score (\%) \\
\hline Blood test & 5 & $2.41 \pm 1.204$ & 48 \\
GCT and GTT & 4 & $0.87 \pm 1.028$ & 22 \\
Urine test & 2 & $1.30 \pm 0.700$ & 65 \\
Ultrasound scan & 10 & $3.57 \pm 2.370$ & 36 \\
Special investigations & 5 & $0.81 \pm 1.043$ & 16 \\
\hline Total & 26 & $8.96 \pm 6.33$ & 34.46 \\
\hline
\end{tabular}

Table 2: Comparison of specific areas of awareness score in specific areas of antenatal investigations among antenatal mothers in first, second and third trimesters calculated using one way ANOVA

\begin{tabular}{llcccc}
\hline \multicolumn{2}{c}{ Mean score, standard deviation and mean score percentage } & & \\
\hline $\begin{array}{l}\text { Specific areas of } \\
\text { awareness }\end{array}$ & First trimester & Second trimester & Third trimester & $d f$ & \\
\hline Blood test & $2.38 \pm 1.24(48 \%)$ & $2.45 \pm 1.18(49 \%)$ & $2.41 \pm 1.19(48 \%)$ & 2 & 0.45 \\
GCT and GTT & $0.66 \pm 0.75(17 \%)$ & $0.91 \pm 0.90(23 \%)$ & $1.05 \pm 1.34(26 \%)$ & 2 & 2.17 \\
Urine test & $1.18 \pm 0.74(59 \%)$ & $1.25 \pm 0.70(63 \%)$ & $1.46 \pm 0.62(73 \%)$ & 2 & 2.73 \\
Ultrasound scan & $3.16 \pm 2.37(32 \%)$ & $3.73 \pm 2.34(37 \%)$ & $3.83 \pm 2.37(38 \%)$ & 2 & 1.38 \\
Special test & $0.88 \pm 1.13(18 \%)$ & $0.70 \pm 1.01(14 \%)$ & $0.86 \pm 0.98(17.2 \%)$ & 2 & 0.563 \\
\hline Total & $8.26 \pm 6.23$ & $9.04 \pm 6.13$ & $9.61 \pm 6.5$ & 10 & 1.007 \\
\hline
\end{tabular}

first, second and third trimesters. The result of the study revealed that the calculated F-value (1.007) is less than the table value (3.04) at 0.05 level of significance. There is no statistically significant difference between awareness on antenatal investigations among antenatal mothers in first, second and third trimesters. However, there is a statistically significant difference in awareness regarding GCT and GTT and urine test among first, second and third trimesters.

\section{DISCUSSION}

Antenatal investigations are important tools for protecting the health of a pregnant woman and her developing child. Various tests are administered over the course of pregnancy. The benefits of antenatal investigations should be explained to each antenatal mother before taking them for tests and scans. A study from Al-Khobar country documented that $12.7 \%$ of antenatal mothers were not aware about blood examination and $11.7 \%$ were believed that blood group and diseases, such as hepatitis B $(4.3 \%)$ and syphilis $(1 \%)$, are the most common reason for blood examination. ${ }^{6}$ The present study demonstrates that the awareness regarding antenatal investigations was poor among antenatal mothers. Only less than 50\% of the subjects were aware about the blood test, glucose tolerance test, glucose challenge test, ultrasound scan and specific investigations like thyroid function test, rubella screening, Coombs test, group B Streptococcus screening. There is a significant difference on awareness regarding GCT, GTT and urine test found between first, second and third trimester. Therefore, it is necessary to prepare antenatal mothers for antenatal investigations both physiologically and psychologically before each test.

Another study conducted by Acevedo $\mathrm{MR}^{7}$ to assess the effectiveness of booklet and counseling $v$ s traditional counseling on improving the knowledge, attitude and practices among 203 pregnant women. Investigator observed that booklet and counseling was better than traditional counseling on improving the knowledge and attitude of the subjects.

Based on the present study result, the investigator prepared an information booklet on antenatal investigations which was focused on those areas where the result of the study showed a deficiency in the awareness level, which will helps to improve the knowledge level of the mother and increases the utilization of facilities by the mothers.

\section{CONCLUSION}

The findings of the study showed that antenatal mothers have inadequate level of awareness regarding antenatal investigations, especially mothers in the first trimester. Thus, awareness program should be conducted among antenatal mothers in all trimesters on topic of antenatal investigations to increase the uptake of routine tests during pregnancy.

\section{ACKNOWLEDGMENT}

We extend our sincere gratitude toward Dr Radhamany $\mathrm{K}$, Professor and Head, Department of Obstetrics and Gynecology, Amrita Institute of Medical Sciences, Kochi; Dr Jayasree Nair, Professor and Dr Chitra R, Associate Professor, Department of Obstetrics and Gynecology, 
Amrita Institute of Medical Sciences, Kochi, for their full support, inspiration and suggestions in completing this work successfully. We also thankful to Thesis Review Committee of Amrita Institute of Medical Sciences, Kochi.

\section{REFERENCES}

1. Bubb, Jennifer A, Mathews AL. What's new in prenatal screening and diagnosis? Primary care [Online]. 2002 Sep;31(3):561.

2. Gupta A, Kumar R, Salhotra VS, Mohan A, Rahi S. National iron + initiative guidelines for control of iron deficiency anemia. Guidelines for control of iron deficiency anaemia national rural health mission. 2013 Jan 15. Available at: http://www.unicef.org/india/10._National_Iron_Plus_Initiative_Guidelines_for_Control_of_IDA.pdf.
3. Viswanath L, Jose A. Self-care agency of women with gestational diabetes mellitus effectiveness of a self care enhancing intervention. Int J Nursing Care 2014 Jan-June;2(1):27.

4. Immunohaematology bulletin [Online] 2011 Jan-Dec;42:1-3.

5. Heazell A. Women's expectations and knowledge of the midtrimester anomaly ultrasound scan in United Kingdom. Ultrasound in Obstetrics and Gynecology [Online] 2003;22(S1): [cited 2003 Aug 29]. Available at: URL: http://onlinelibrary. wiley.com/doi/10.1002/uog.526/pdf.

6. Praveen R. Health education needs for pregnancy a study among women attending primary health centers. J Family Comm 2003;10(1):31-38.

7. Acevedo MR. The effect of mother's pregnancy booklet and counselling versus traditional counseling on improving the knowledge, attitude and practices of pregnant women on prenatal care in the selected Barangays of Kabasalan. Available at: http://www.som.adzu.edu.ph/research/pdf/201005-084418Mary_Therese_Radajail_Acevedo.pdf. 